\title{
Spatio-temporal Variation of Wind Erosion in Inner Mongolia of China Between 2001 and 2010
}

\author{
JIANG Ling ${ }^{1,2}$, XIAO Yi ${ }^{1}$, ZHENG Hua ${ }^{1}$, OUYANG Zhiyun ${ }^{1}$ \\ (1. State Key Laboratory of Urban and Regional Ecology, Research Center for Eco-Environmental Sciences, Chinese Academy of Sci- \\ ences, Beijing 100085, China; 2. University of Chinese Academy of Sciences, Beijing 100049, China)
}

\begin{abstract}
Using Geographic Information System (GIS), based on wind speed, precipitation, topographic, soil, vegetation coverage and land use data of Inner Mongolia between 2001 and 2010, we applied the revised wind erosion equation (RWEQ) model to simulate wind erosion intensity. The results showed that an area of approximately $47.8 \times 10^{4} \mathrm{~km}^{2}$ experienced wind erosion in $2010,23.2 \%$ of this erosion could be rated as severe, and $46.0 \%$ as moderate. Both the area and the intensity of wind erosion had decreased from 2001 to 2010, the wind erosion area reduced $10.1 \%$, and wind erosion intensity decreased by $29.4 \%$. Precipitation, wind speed, population size and urbanization in rural areas, and gross domestic product of primary industry (GDP1) were the main factors influencing wind erosion. Overall, these factors accounted for $88.8 \%$ of the wind erosion. These results indicated that the decrease in wind erosion over the past decade related to the increase in precipitation and the decrease in the number of windy days, while modest urban development and optimization of the economic structure might partially reduced the level of ecological pressure, highlighting the importance of human activities in controlling wind erosion.
\end{abstract}

Keywords: wind erosion; revised wind erosion equation (RWEQ); driving factor

Citation: Jiang Ling, Xiao Yi, Zheng Hua, Ouyang Zhiyun, 2016. Spatio-temporal variation of wind erosion in Inner Mongolia of China between 2001 and 2010. Chinese Geographical Science, 26(2): 155-164. doi: 10.1007/s11769-016-0797-y

\section{Introduction}

Wind erosion is one of the most serious environmental problems in arid and semiarid regions of the world (Buschiazzo and Zobeck, 2008). Wind erosion can lead to desertification (Lal, 1998; Callot et al., 2000), and is known to be responsible for the decrease in productivity often reported from arable soils due to loss of organic matter (Pimentel and Kounang, 1998). Wind erosion can also cause other major environmental problems, such as sand storms and episodes of reduced air quality (Hoffmann et al., 2011), which in turn can affect human health due to harmful effects of dust particles on the respiratory system (Copeland et al., 2009; De Longueville et al., 2009).

Wind erosion is a complex physical process, and represents one of the most important exogenetic forces generating and shaping a range of geological features. Different climate factors, such as wind speed, precipitation, and temperature and human activities including farming, pasturage, wood cutting, and digging can influence the effects of wind erosion over the landscape. Thus, changes in wind erosion patterns due to climate causes are temporary, while high levels of human impact associated with poor management strategies can accelerate wind erosion processes, potentially leading to

Received date: 2014-10-14; accepted date: 2015-02-22

Foundation item: Under the auspices of National Key Technology Research and Development Program of China (No. 2011BAC09B08), Special Issue of National Remote Sensing Survey and Assessment of Eco-Environment Change Between 2000 and 2010 (No. STSN-04-01)

Corresponding author: XIAO Yi. E-mail: xiaoyi@rcees.ac.cn

(C) Science Press, Northeast Institute of Geography and Agroecology, CAS and Springer-Verlag Berlin Heidelberg 2016 
environmental catastrophes and endanger human life andhealth, and agricultural production (Hu et al., 2003).

Woodruff and Siddoway (1965) proposed the wind erosion equation (WEQ), which came to be the most comprehensive and widely used model for estimating soil loss by wind from agricultural fields. However, the WEQ presented a series of limitations as empirical model. There revised wind erosion equation (RWEQ) combines empirical and modelling aspects, and represents the first wind erosion model that has been extensively tested under field conditions within and outside the Great Plains.

Inner Mongolia is located in the northeast of China. It includes areas of typical arid and semiarid climates and it is characterized by high levels of evaporation, low rainfall, and strong winds during spring.The region includes large extensions of desert environments, including the Gobi desert, which is particularly vulnerable to wind erosion. According to the latest Bulletin of $\mathrm{Na}-$ tional Soil and Water Conservation in China, nearly half area of Inner Mongolia is affected by wind erosion. Meanwhile, with the development of the economy and increasing population over the past years, human activities have caused profound disturbances to the natural environment and intensify the damage caused by wind erosion. Human practices such as excessive clearance of native vegetation, over grazing and inadequate agricultural practices have resulted in increased frequency and intensity of wind erosion in some regions (Shao, 2008), which can ultimately threaten the sustainable development of these regions.

Previous studies have studied wind erosion in different methods. On the one hand, mainly method in wind erosion studies of arid areas are qualitative analyses $(\mathrm{Li}$, 2000; Zhang et al., 2001; Karssenberg and De Jong, 2005; Shi et al., 2009; Yang et al., 2010; Juan, 2012); on the other hand, wind tunnel experiments, ${ }^{137} \mathrm{Cs}$ tests, and wind erosion models have been used to estimate wind erosion intensity (Yan and Dong, 2003; Van Pelt et al., 2004; Liu et al., 2006; Daniel et al., 2007; Liu et al., 2007; Buschiazzo, 2008), however, wind erosion models applied to estimate wind erosion are still scarce in domestic.

Here, we analysed GIS data using the RWEQ (Bondy et al., 1980; Cole et al., 1983; Comis and Gerrietts, 1994; Fryrear et al., 1998) to determine average annual soil loss intensity and distribution patterns between
2001 and 2010 in Inner Mongolia, to assess spatiotemporal variations and factors influencing wind erosion. Thus, this study provides a reference for future management strategies aimed to control and reduce the effect of wind erosion, and to ensure social and economic sustainable development of the region.

\section{Materials and Methods}

\subsection{Study area}

The Inner Mongolia Autonomous Region (37 $24^{\prime}-$ $53^{\circ} 23^{\prime} \mathrm{N}, 97^{\circ} 12^{\prime}-126^{\circ} 04^{\prime} \mathrm{E}$ ) is situated on the Mongolian Plateau in the northern China, with a total area approximately $1.183 \times 10^{6} \mathrm{~km}^{2}$ and presents a typical continental monsoon climate, with an average annual precipitation of $50-450 \mathrm{~mm}$, and average annual temperature of $0-8^{\circ} \mathrm{C}$. From east to west, the main bioclimatic zones vary from humid, sub-humid, semi-arid, toarid, and extreme arid zones from east to west. This geographically variable environment is partially responsible for the abundance of natural resources of the region. Soil types also vary at the geographical scale, including black, dark brown, brown, and sierozem soil and grey-brown desert soil in that order if observed from east to west (Wang et al., 2012).

Land use varies across the region. East Inner Mongolia is characterized by the presence of large extension of forests, while grassland dominates in the central parts, desert in the west, pasture land in the north, and farmland in the south. Inner Mongolia is one of the areas with serious wind erosion problem and drastic land use change in China. This region has been dramatically influenced by policies supporting food production while neglecting grassland conservation, transforming grasslands to arable at large scales, leading to grassland desertification approximately $1.00 \times 10^{6}$ ha (Miao, 1996). Thus, overexploitation of grasslands has become a serious environmental issue. The results of previous studies showed that the rate of overexploitation of grasslands in the region increased from $23.6 \%$ in 1986 to $56.7 \%$ in 1992 (Xu and Bai, 1997), mainly driven by the population growth experienced in the region between 1980 and 1990 , leading to grassland degradation and desertification. Some areas even become unlivable, such as eastern and western Suninte, and Siziwang districts, where surface soil had lost the protection of natural vegetation and enhancing wind erosion. Between 1993 and 2000, over 20 sandstorms a year were recorded from middle 
and west Inner Mongolia. In general, wind erosion rate increased rapidly within this period, severely affecting normal life and agricultural production in Inner Mongolia (Jiang, 1988; Li, 1997; Chen, 2000; Li et al., 2001; Li et al., 2011) (Fig. 1).

\subsection{Model and analyses}

\subsubsection{Revised wind erosion equation model}

The RWEQ model estimates soil loss for a certain location $\left(S_{\mathrm{L}}\right)$. Firstly, weather, soil erodible, soil crust, surface roughness and vegetation cover factors are used to calculate the maximum transported capacity by wind $\left(Q_{\max }\right)$ and the critical field length $(S)$ as follows (Fryrear, 1998):

$$
\begin{aligned}
& Q_{\max }=109.8\left(W F \times E F \times S C F \times K^{\prime} \times C\right) \\
& S=150.71\left(W F \times E F \times S C F \times K^{\prime} \times C\right)^{-0.3711} \\
& S_{\mathrm{L}}=\frac{2 \cdot z}{S^{2}} Q_{\text {max }} \cdot \mathrm{e}^{-(z / s)^{2}}
\end{aligned}
$$

where $Q_{\max }(\mathrm{kg} / \mathrm{m})$ is the maximum transport capacity, $S$ (m) is the critical field length (defined as the distance at which $63 \%$ of the maximum transport capacity is reached), $S_{\mathrm{L}}\left(\mathrm{kg} / \mathrm{m}^{2}\right)$ is the rate of soil loss caused by wind erosion, $z(\mathrm{~m})$ is the distance from the upwind edge of the field, $W F$ is a weather factor, $S C F$ represents soil crusting, $E F$ is the soil erodible factor, $C$ is the vegetation factor, and $K^{\prime}$ represents surface roughness.

Weather factor $(W F)$. Wind is the basic driving force in RWEQ, whilst soil moisture and snow cover are important factors influencing wind erosion. The weather factor represents the influence of climatic condition on wind erosion, and combines wind speed, soil moisture, and snow cover as follows:

$$
W F=W f \times \frac{\rho}{\mathrm{g}} \times S W \times S D
$$

where $W F$ is the weather factor $(\mathrm{kg} / \mathrm{m}), W f$ is the wind factor $\left(\mathrm{m}^{3} / \mathrm{s}^{3}\right), \rho$ is air density $\left(\mathrm{kg} / \mathrm{m}^{3}\right), \mathrm{g}$ is the acceleration due to gravity $\left(\mathrm{m} / \mathrm{s}^{2}\right), S W$ is soil moisture, and $S D$ represents snow cover.

Soil erodible factor $(E F)$. The erodible fraction is that fraction of the surface $25 \mathrm{~mm}$ of soil that is lower than $0.84 \mathrm{~mm}$ in diameter as determined by a standard compact rotary sieve (Chepil, 1962). From a soil sieving

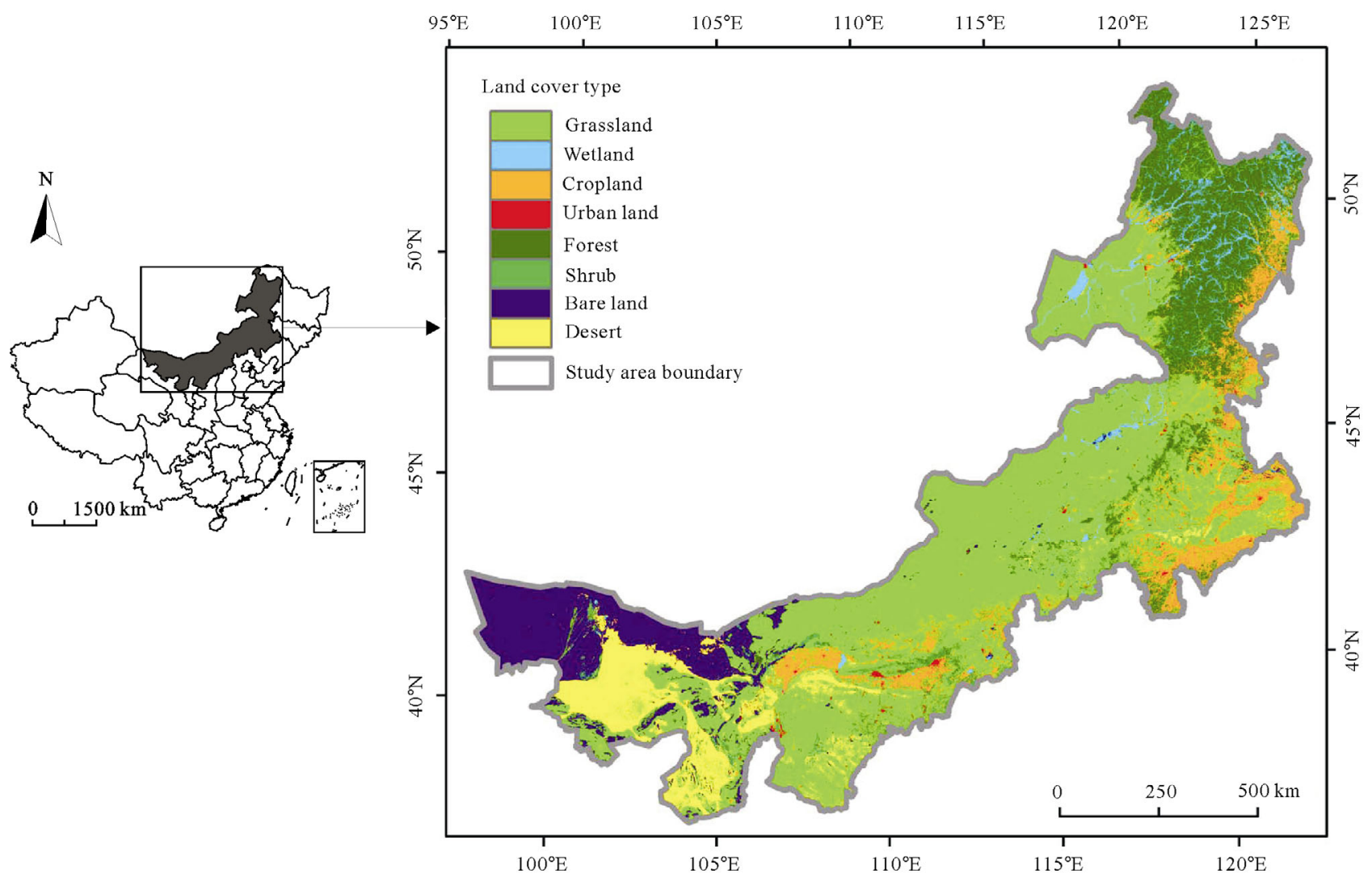

Fig. 1 Map of study area and ecosystem distribution 
data base, the highest value for EF during a year for each site was correlated with basic soil physical and chemical properties (Fryear et al., 1994). The developed formula is as follows.

$E F=\frac{29.09+0.31 S a+0.17 S i+0.33(\mathrm{Sa} / \mathrm{cl})-2.59 \mathrm{OM}-0.95 \mathrm{CaCO}_{3}}{100}$

where $E F$ is the erodible factor, $S a$ is the sand content $(\%), S i$ is the silt content (\%), $\mathrm{cl}$ is the caly content (\%), $\mathrm{OM}$ is the organic matter (\%), $\mathrm{CaCO}_{3}$ is the calcium carbonate $(\%)$.

Soil Crusting Factor $(S C F)$. When raindrops impact the soil surface, there is a redistribution of soil particles and a formation of surface crust. The resulting soil surface can be extremely hard or very fragile and may decrease or increase wind erosion potential (Zobeck, 1991). The SCF equation was developed using laboratory wind tunnel tests on resistance of soil aggregates and crusts to windblown sand (Hagen et al., 1992).

$$
S C F=\frac{1}{1+0.0066(c l)^{2}+0.021(O M)^{2}}
$$

where $S C F$ is the soil crusting factor, $\mathrm{cl}$ is the clay content (\%), OM is the organic matter (\%).

Vegetation Factor $(C)$. The vegetation quantity on the soil surface has a significant impact on soil erosion by wind. To quantify the effect of vegetation, the fraction of the soil surface covered with nonerodible plant material (flat residues), the plant silhouette from standing plant residues (standing residues), and growing crop canopies (crop canopy) are used in RWEQ (Bilbro and Fryear, 1994). In this study, limited to available data, the flat residues of soil loss ratio coefficient $\left(S L R_{\mathrm{f}}\right)$ is calculated as a function of the soil that is covered with any type of vegetation.

$S L R_{\mathrm{f}}=\mathrm{e}^{-0.0483(S C)}$

where $S L R_{\mathrm{f}}$ is the vegetation factor, $S C$ is the vegetation coverage $(\%)$.

Surface Roughness Factor $\left(K^{\prime}\right)$. Original RWEQ was designed to calculated wind erosion loss in a field scale. Tillage operations modify the soil surface roughness and flatten and bury crop residues (Nelson et al., 1993). When scale up to a regional, roughness caused by topography will replace the soil ridge roughness, and calculated by Smith-Carson equation. The Smith-Carson equation and surface roughness factor $\left(K^{\prime}\right)$ formula as follows (Li et al., 2006):

$$
\begin{aligned}
K_{\mathrm{r}} & =0.2 \cdot \frac{(\Delta H)^{2}}{L} \\
K^{\prime} & =\mathrm{e}^{\left(1.86 K_{\mathrm{r}}-2.41 K_{\mathrm{r}}^{0.934}-0.127 C \mathrm{rr}\right)}
\end{aligned}
$$

where, $K_{\mathrm{r}}$ is the topographic roughness length $(\mathrm{cm}), K^{\prime}$ is the surface factor, $\Delta H$ is the elevation difference within the $L$ distance, $C_{\mathrm{rr}}$ is the chain random roughness.

\subsubsection{Statistical analysis}

(1) Driving force analysis

Multiple factors influenced wind erosion, however, we could divided these factors into two categories: climate and human activity. In order to understand which factors are the most important leading changes in wind erosion patterns, we used redundancy analysis (RDA) (Jan et al., 2003), constrained linear ordination method. Intensity and area of the study area affected by wind erosion were defined as response variables, and a total of 15 factors, temperature, precipitation, wind speed, number of windy days, rural population density, gross domestic product of three different industry (GDP1-3), urbanization level, number of grazing sheep, and farmland area, were included as explanatory variables, these factors were analysed to estimate their relative contribution to wind erosion using 999 Monte Carlo permutations, and all data were standardized before used.

(2) Wind erosion intensity trends

Simple linear regression analyses tool of ARCGIS were used to simulate trends inwind erosion intensity between 2001 and 2010 based on basic raster. The slope expression was estimated as (Mu et al., 2012):

$\theta=\frac{n \times \sum_{i=1}^{n} i \times C_{i}-\sum_{i=1}^{n} i \sum_{i=1}^{n} C_{i}}{n \times \sum_{i=1}^{n} i^{2}-\left(\sum_{i=1}^{n} i\right)^{2}}$

where $\theta$ is the trend slope, $n$ is the total number of years, $C_{i}$ represents wind erosion intensity in the $i$ th year, with $i$ set to $1-10$. An area of $\theta<0$ indicates a decrease in wind erosion intensity has decreased over the10-year period, while an area of $\theta>0$ indicates an increase in wind erosion intensity over the 10 -year period studied.

\subsubsection{Background data}

We obtained daily precipitation, temperature, and wind 
speed data of Inner Mongolia for the period of 20012010 from the China Meteorological Data Sharing Service System (http://cdc.cma.gov.cn). Land use and vegetation cover data (2001-2010) were provided by the Institute of Remote Sensing and Digital Earth, Chinese Academy of Sciences. Soil properties, annual solar radiation data, and annual snow cover data were provided by the Cold and Arid Regions Sciences Data Center in Lanzhou (http://westdc.westgis.ac.cn). The Digital Elevation Model $(90 \mathrm{~m})$ was provided by the Computer Network Information Center, Chinese Academy of Sciences. Inner Mongolia socioeconomic development statistical data (2001-2010) were obtained from statistical yearbooks (IMARBS, 2001-2010).

\subsubsection{Model calibration and validation}

Different parameters were used to calculate soil loss driven by wind erosion using the RWEQ model. The results were divided into five categories according to the national industrial standard of Classification Standard of Soil Erosion (MWRPRC, 2008) as follows: slight erosion, moderate erosion, strong erosion, intense erosion, and severe erosion (Table 1).

Wind erosion intensities thus classified for the year 2000 were checked against the results of the China soil erosion investigation (for the year 2000) acquired from remote sensing data for qualitative verification. The results from both studies were highly consistent $\left(R^{2}=\right.$ 0.89) despite using different approaches (Fig. 2), illustrating the viability of the RWEQ model to assess wind erosion intensity in Inner Mongolia.

\section{Results}

\subsection{Temporal variability}

Between 2001 and 2010, both areas exposed to wind (Fig. 3). erosion and intensity showed a clear decreasing trend. The area exposed to wind erosion decreased from $5.33 \times 10^{5} \mathrm{~km}^{2}$ in 2001 to $4.78 \times 10^{5} \mathrm{~km}^{2}$ in 2010 , representing a reduction of $10.1 \%$. The area exposed to wind erosion changed over the 10-year period, and $4.4 \times$ $10^{4} \mathrm{~km}^{2}$ of the area changed to high wind intensity, representing to $7.9 \%$ of the area affected by wind erosion. On the other hand, $1.76 \times 10^{5} \mathrm{~km}^{2}(33.1 \%$ the total area exposed to wind erosion) experienced a decrease from high to low wind intensity. Soil loss caused by wind erosion decreased $29.5 \%$ during the study period, from $5.70 \times 10^{9} \mathrm{t}$ in 2001 to $4.02 \times 10^{9} \mathrm{t}$ in 2010 .

\subsection{Spatial difference}

The results showed a relatively high wind erosion rate in Inner Mongolia during the study period. Nearly half of the Inner Mongolia has experienced wind erosion, although most of the erosion occurred in the western Inner Mongolia (Fig. 4). The total wind erosion area was $4.78 \times 10^{5} \mathrm{~km}^{2}$ in 2010 , with $23.2 \%$ and $13.8 \%$ of the area experiencing severe and intense erosion, respectively, $8.9 \%$ of the area experienced strong erosion, and $20.0 \%$ and $34.0 \%$ moderate and slight erosion, respectively.

The 10-year trend for wind erosion intensity varied spatially. As shown in Fig. 5, the wind erosion intensity increased over an area of $1.12 \times 10^{5} \mathrm{~km}^{2}$, mostly across the Alxa Plateau, and the west Inner Mongolia. The weakest levels of wind erosion intensities extended over $1.73 \times 10^{5} \mathrm{~km}^{2}$, mostly distributed across the Erdos Plateau, west of the Hunshadake Sandy Land, and the Korqin Sandy Land.

The results of the spatial analysis showed an increase in wind erosion intensity from the east to west, with high intensity areas mainly distributed throughout the arid areas in the western Inner Mongolia. These areas

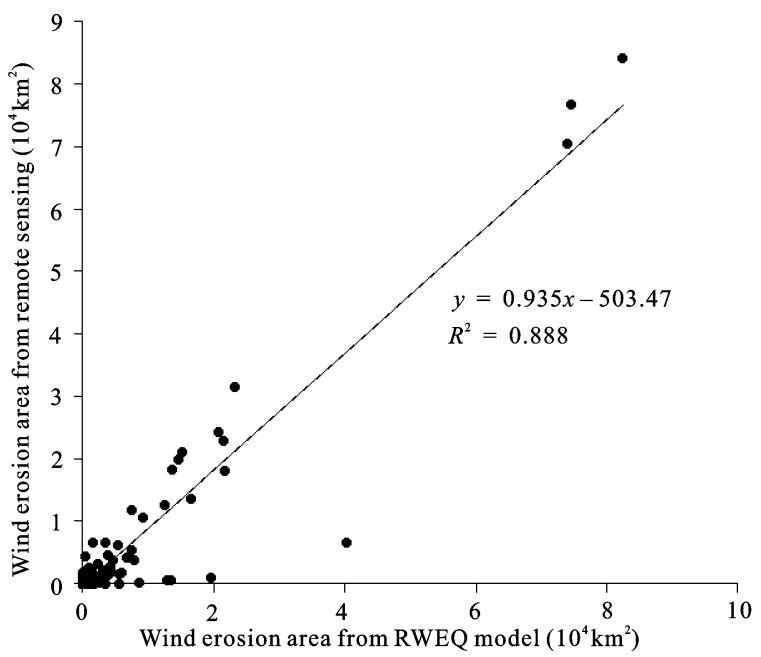

Fig. 2 Relationship between remote sensing data and revised wind erosion equation (RWEQ) results

Table 1 Wind erosion categories $\left(\mathrm{t} /\left(\mathrm{km}^{2} \cdot \mathrm{yr}\right)\right)$

\begin{tabular}{cccccc}
\hline Erosion gradation & Slight erosion & Moderate erosion & Strong erosion & Intense erosion & Severe erosion \\
\hline Erosion modulus & $200-2500$ & $2500-5000$ & $5000-8000$ & $8000-15000$ & $>15000$ \\
\hline
\end{tabular}


mainly present desert aeolian sandy soils and prairie aeolian sandy soils, which are highly vulnerable to wind erosion. Windy, drought conditions, and high temperature unfavorable for plant growth in this area, and soils lacking protection from overlaying vegetation cover become erodible. In general, the spatial distribution pattern of wind erosion was based on soil types, vegetation convert, and climate conditions.
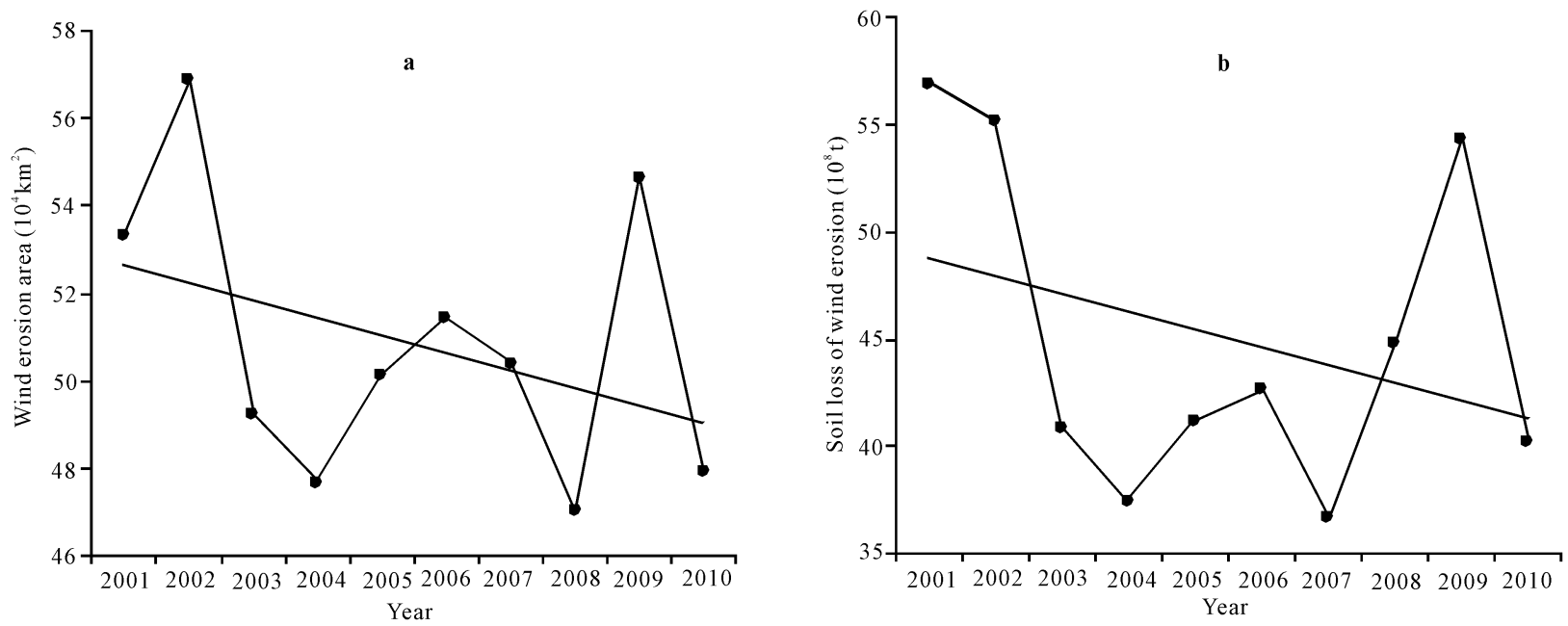

Fig. 3 Variation in soil loss and area affected by wind erosion in Inner Mongolia for period of 2000-2010. (a) wind erosion area; (b) soil loss of wind erosion

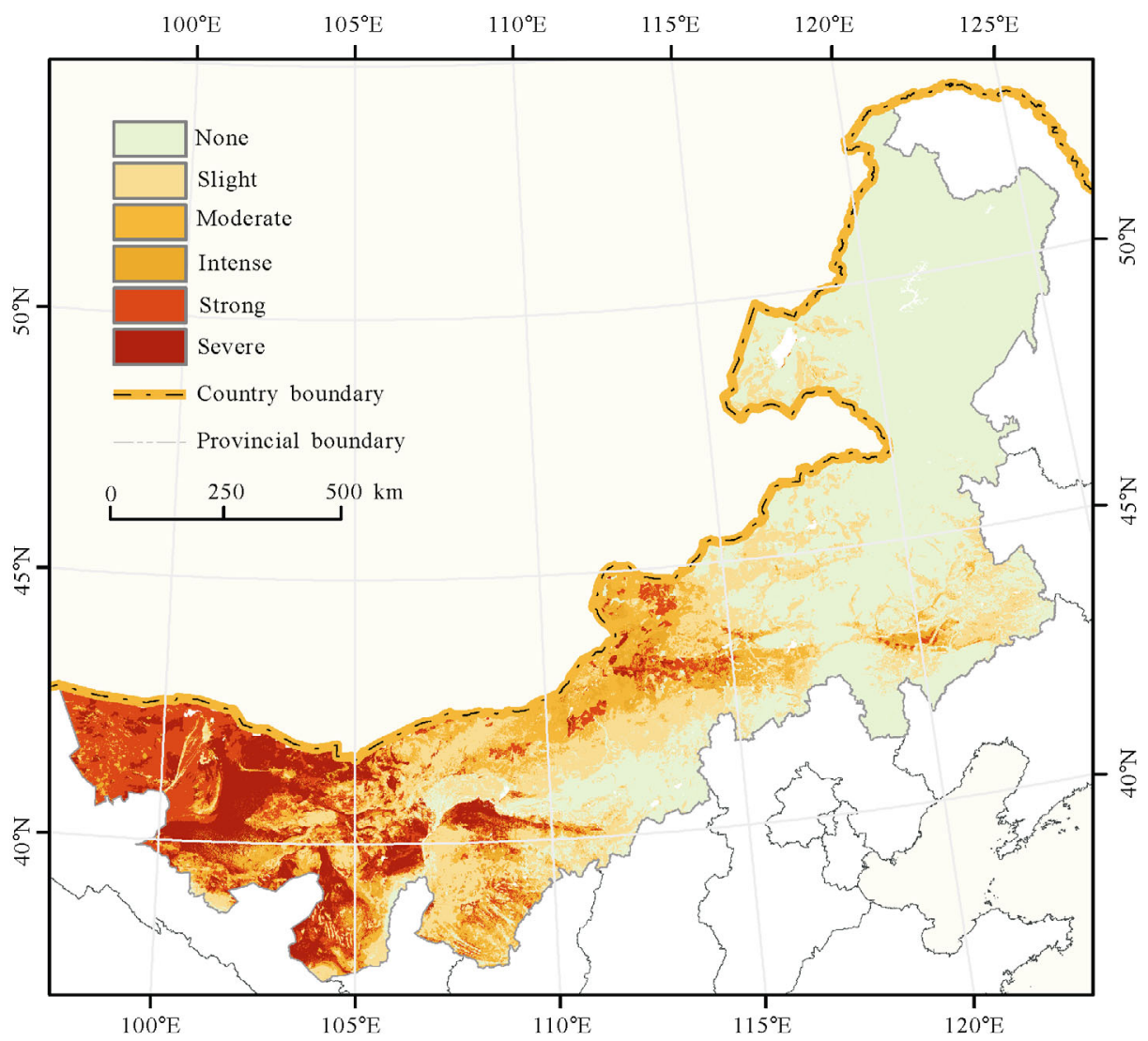

Fig. 4 Spatial pattern of wind erosion in Inner Mongolia 


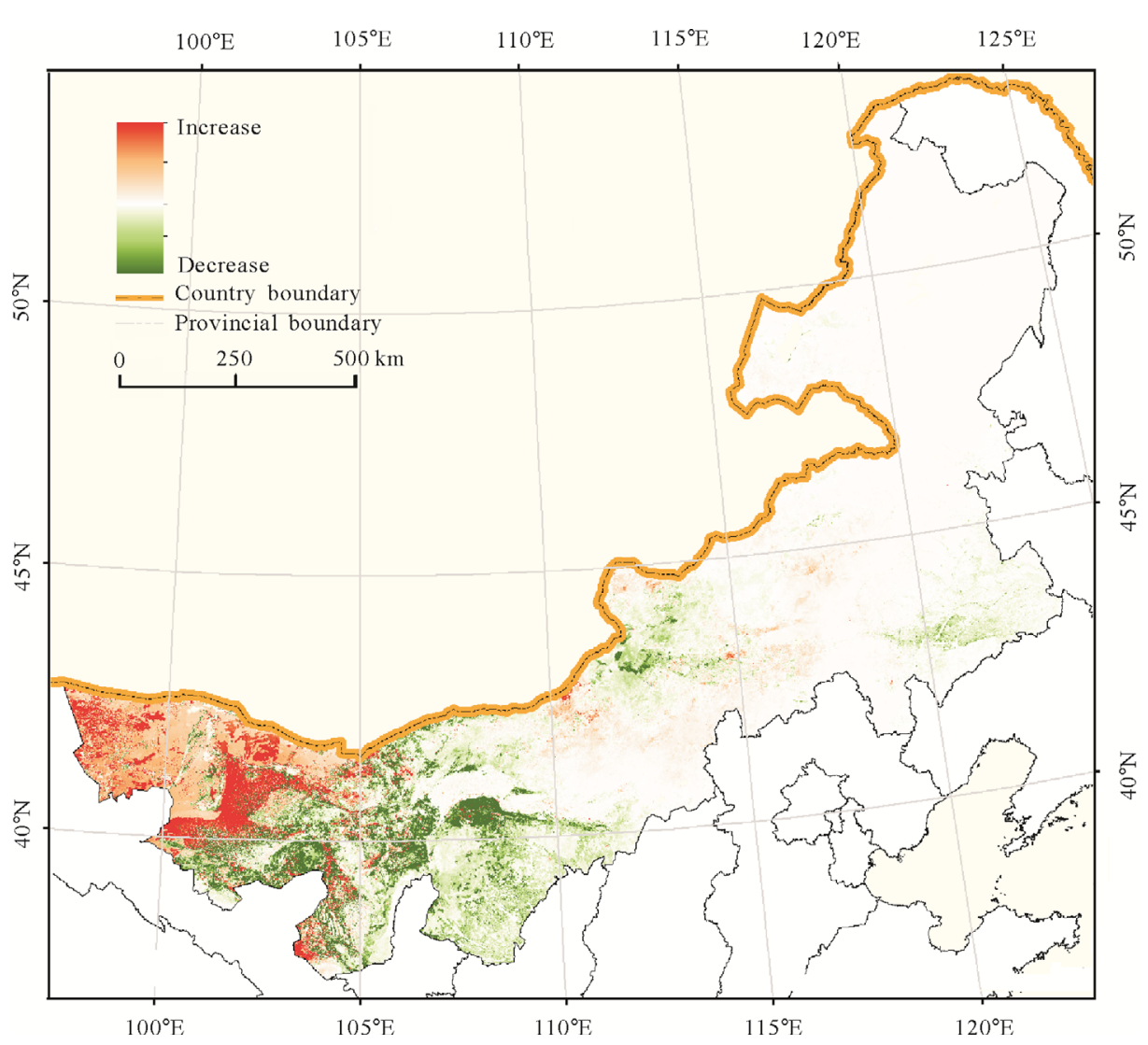

Fig. 5 Wind erosion intensity trends for period of 2000-2010

\subsection{Driving force analysis}

The RDA results showed that precipitation and wind were the main climate factors driving the decadal trend in wind erosion while rural population percent, urbanization level, and GDP1 rate were the main human activity factors. These factors combined explained $88.8 \%$ of the total variation in wind erosion measured during the study period (Fig. 6). Thus, the interaction of human and climate factors led to a decrease in wind erosion area

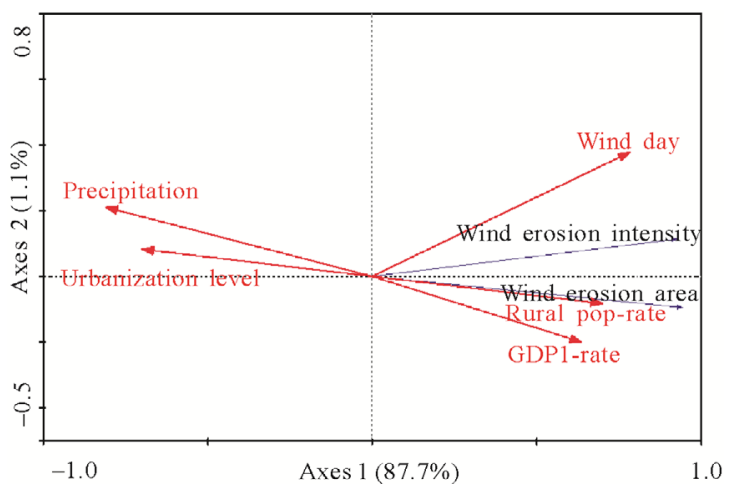

Fig. 6 Redundancy analysis (RDA) result about relationship between wind erosion change and driving facto. Rural pop-rate: the rate of rural population; GDP1-rate: the rate of GDP1 and intensity in Inner Mongolia over the last decade. While climate was the main responsible for the change, human factors enhanced the variability observed.

\section{Discussion}

\subsection{Effect of precipitation on wind erosion}

Climate change affects wind erosion slowly and gradually, mainly by influencing soil moisture, vegetation cover, and hydrological dynamics.From all influencing factors, precipitation is known to play an essential role (Su et al., 2006). Our results showed a negative correlation between precipitation and wind erosion (Fig. 6). Overall precipitation can influence wind erosion considerably. For example, an increase in rainfall can directly lead to an increase in soil moisture, enhancing soil ability to withstand soil erosion. In addition, rainfall can stimulate plant growth, especially in arid and semi-arid areas, increasing vegetation cover and subsequently the level of protection against wind erosion. The level of precipitation fluctuated between 2001 and 2010, with a maximum precipitation of $366.9 \mathrm{~mm}$ measured in 2003 
and a minimum precipitation of $234 \mathrm{~mm}$ measured in 2005 , consistent with that, wind erosion area and intensity decreased between 2001 and 2005, and increased again between 2006 and 2010 .

\subsection{Effect of human activities on wind erosion}

Human activity can significantly influence environmental development and evolution, representing a major driving factor. As a consequence of exponential population, the extension of land dedicated to agricultural production has increased rapidly, increasing human pressure over grasslands to meet agricultural demands. This change in land use has led to environmental degradation and reduced ecological productivity, accelerating desertification as a consequence of increased wind erosion (Liu and Ci, 1997). In the absence of targeted management and conservation strategies, human activities, including forest clearing, land use change of pasture land and vegetation clear-cutting, could potentially accelerate and aggravate wind erosion.

However, efficient management strategies and technological advances could help restricting and controlling detrimental activities, e.g., through afforestation, banning grazing, restoration of forests and grassland from farmlands, could potentially reverse the effects of wind erosion and prevent it (Su et al., 2006). Urbanization can increase rural-to-urban migration, reducing the pressure over the regional natural environment, improving production efficiency, and concentrating industry in hotspots enhancing pollution control. In addition, cities also present the advantage of prevent wind erosion. All of these factors are known to have a positive influence on sensitive arid and sub-arid regions (Chen, 2004; Hou et al., 2013).

Over the past decade, Inner Mongolia has experienced fast urbanization, and urban extension has increased from $42 \%$ in 2001 to $57 \%$ in 2010 . By contrast, rural population decreased from $1.555 \times 10^{6}$ in habitant in 2001 to $1.274 \times 10^{6}$ in 2010 , representing a decrease in $15.2 \%$, reflecting a clear urbanization tendency. During the same period, the GDP percent of primary industries has fallen by approximately $23 \%$, indicating that economic activity has been transferred from agricultural and pastoral practices to industry and service sectors.

Agriculture and pastoral practices are sensitive to environmental degradation in fragile ecosystems. Thus, a decrease in human activity combined with efficient management strategies at the regional level at the appropriate temporal and spatial scale could expedite environmental recovery and help controlling wind erosion.

\subsection{Remediation strategies to control wind erosion} Our results highlighted climate change as a major factor responsible for the decrease in wind erosion observed in Inner Mongolia between 2001 and 2010. In addition, human activity can also help reducing wind erosion, highlighting the need of targeted management strategies to direct human activity toward wind erosion control, including: 1) Accelerating industrial restructuring, reducing primary industrial production, restricting grassland cultivation, and limiting livestock population to prevent grassland degradation; 2) Enhancing environmental protection, accelerating natural vegetation growth and recovery by ensuring grassland and forest restoration from farmland and a timely recovery of degraded grassland, promoting rotational grazing of grassland, and placing livestock in corrals instead of allowing them to roam freely; 3) Improving production efficiency and reducing ecological pressure. To this end, we should increase the level of urbanization in a controlled way, and encourage population to concentrate in urban areas.

\subsection{Limitation of RWEQ method}

In this study, we applied the RWEQ model to assess wind erosion in Inner Mongolia between 2001 and 2010. Our results show high consistency with remote sensing data, indicating that the RWEQ model applied can be used to assess wind erosion in this region. However, China extends over a vast territory, with varying climate conditions, and large elevation differences. Thus, although this model was successfully validated for Inner Mongolia, further long-term experimental and monitoring data from other regions of China are required to validate the model for other areas. This validation should include a variety of geographical features and ecosystems and a careful revision of RWEQ parameters and equations to ensure the accuracy of the model. In addition, different vegetation types (grassland, shrub, forest, and farmland) present different resistances to wind erosion, which is not captured in the model. This aspect would also require further improvement in future work. 


\section{Conclusions}

Our results show a reduction in wind erosion and soil loss in Inner Mongolia between 2001 and 2010. The area affected by wind erosion decreased by $10.1 \%$ during this period, while soil loss decreased by $29.5 \%$. The area affected by wind erosion decreased from $5.33 \times 10^{5} \mathrm{~km}^{2}$ in 2001 to $4.79 \times 10^{5} \mathrm{~km}^{2}$ in 2010 . Wind erosion intensity varied throughout the study period. To this end, and total area of $4.4 \times 10^{4} \mathrm{~km}^{2}$ experienced an increase in wind erosion intensity from low to strong intensity, representing a $7.9 \%$ of the total area affected by wind erosion. On the other hand, $1.76 \times 10^{5} \mathrm{~km}^{2}$ of the total area affected changed from strong to low intensity, representing $33.1 \%$ of the wind affected area. Wind erosion driven soil loss decreased from $5.70 \times 10^{9} \mathrm{t}$ in 2001 to $4.02 \times 10^{9} \mathrm{t}$ in 2010 .

Wind erosion intensity varied at the spatial scale; wind erosion intensity and area affected increased from the east to west. High intensity areas were mainly distributed on arid areas in the western Inner Mongolia. In general, this spatial distribution pattern was consistent with the distribution patterns of erodible soil, vegetation cover, and precipitation in Inner Mongolia.

Our driving force analysis identified five main factors driving the changes in wind erosion observed over the study period. Precipitation and number of windy days (as main environmental factors) and rural population growth rate, urbanization level, and GDP1 rate (as main human-driven factors) can explain $88.8 \%$ of the variation in wind erosion over the period studied. Climate change was the main driver of changes in wind erosion over this period, mainly through an increase in rainfall and a decrease in wind frequency.

Human activity also contributed to changes in wind erosion. Our results showed a reducing effect of human activity on wind erosion in Inner Mongolia. This effect could be achieved through increasing urbanization moderately, promoting the concentration of rural populations in urban areas, reducing the intensity of agriculture and pasture practices, optimizing the industrial structure, promoting forest and grassland restoration from farmland, restricting grassland cultivation, limiting the number of livestock heads on grassland, and allowing a timely recovery for degraded grassland, promoting rotational grazing and corral livestock.

\section{References}

Bilbro J D, Fryear D W, 1994. Wind erosion losses as related to plant silhouette and soil cover. Agronomy Journal, 86(3): 550-553. doi: 10.2134/agronj 1994.00021962008600030017x

Bondy E, Lyles L, Hayes W A, 1980. Computing soil erosion by periods using a wind energy distribution. Journal of Soil \& Water Conservation, 35(4): 173-176.

Buschiazzo D E, Zobeck T M, 2008. Validation of WEQ, RWEQ and WEPS wind erosion for different arable land management systems in the Argentinean Pampas. Earth Surface Process and Landforms, 33(12): 1839-1850. doi: 10.1002/esp.1738

Callot Y, Marticorena B, Bergametti G, 2000. Geomorphologic in a model of dust emissions: application to the Sahara Desert. Geodinamica Acta, 13(5): 245-270.

Chen Dapeng, 2004. Introduction the ecological roles of urbanization in desertification area at north of Shanxi Province. Ecological Economy, (10): 35-38. (in Chinese)

Chen Ruiqing, 2000. Warning of the sandstorm-Inner Mongolia is the most important ecological defence line in North China. Advancing Forum, (5): 15-18. (in Chinese)

Chepil W S, 1962. A compact rotary sieve and the importance of dry sieving in physical soil analysis. Soil Science Society of America Proceedings, 26(1): 4-6. doi: 10.2136/sssaj1962.036 $1599500260001002 \mathrm{x}$

Cole G W, Lyles L, Hagen L J, 1983. A simulation model of daily wind erosion soil loss. Transactions of the Asae, 26(6): 1758-1765. doi: 10.13031/2013.33839

Comis D, Gerrietts M, 1994. Stemming wind erosion. Agricultural Research, 42(6): 8-15.

Copeland N S, Sharratt B S, Wu J Q et al., 2009. A wood-strand material for wind erosion control: effects on total sediment loss, PM10 vertical flux, and PM10 loss. Journal of Environmental Quality, 38(1): 139-148. doi: 10.2134/jeq2008.0115

Daniel E B, Ted M Z, Sergio A A, 2007. Wind erosion quantity and quality of an Entic Haplustoll of the semi-arid pampas of Argentina. Journal of Arid Environments, 69: 29-39. doi: 10. 1016/j.jaridenv.2006.08.013

De Longueville F, Henry S, Ozer P, 2009. Saharan dust pollution: implications for the Sahal? Epidemiology, 20(5): 780. doi: 10.1097/EDE.0b013e3181afef49

Fryear D W, Ali S, Bilbro J D et al., 1998. Revised Wind Erosion Equation (RWEQ). Wind Erosion and Water Conservation Research Unit, USDA-ARS, Southern Plains Area Cropping Systems Research Laboratory. Technical Bulletin No. 1.

Fryear D W, Krammes C A, Williamson D L et al., 1994. Computing the wind erodible fraction of soils. Journal of Soil and Water Conservation, 49(2): 183-188.

Hagen L J, Skidmore E L, Saleh A, 1992. Wind erosion: prediction of aggregate abrasion coefficients. Transactions of the ASAE, 35(6): 1847-1850. doi: 10.13031/2013.28805

Hoffmann C, Funk R, Reiche M et al., 2011. Assessment of extreme wind erosion and its impacts in Inner Mongolia, China. Aeolian Research, 3(3): 343-351. doi: 10.1016/j.aeolia.2011. 
07.007

Hou Yang, Zhang Yuqing, Wu Bin et al., 2013. Eco-environmental impact of urbanization process in a sandy area. Bulletin of Soil Water Conservation, 33(1): 97-102. (in Chinese)

$\mathrm{Hu}$ Yunfeng, Liu Jiyuan, Zhuang Dafang, 2003. Progress in wind erosion research. Progress in Geography, 22(3): 288-295. (in Chinese)

IMARBS (Inner Mongolia Autonomous Regin Bureau of Stutistes), 2001-2010. Inner Mongolia Statistical Yearbook (2001-2010). Inner Mongolia: Inner Mongolia Autonomous Regin Bureau of Statistes Press. (in Chinese)

Jiang Shu, 1988. The degradation of grassland and control strategies. Natural Resource, (2): 1-7. (in Chinese)

Juan C S, Nora E E, Adrian G V et al., 2012. Wind erosion risk in the southwest of Buenosaires Province, Argentian and its relationship to the productivity index. Aeolian Research, 3(2012): 419-425. doi: 10.1016/j.aeolia.2011.10.002

Karssenberg D, De Jong K, 2005. Dynamic environmental modelling in GIS: 2 modelling error propagation. International Journal of Geographical Information Science, 19(6): 623-637. doi: 10.2080/13658810500104799

Lal R, 1998. Soil erosion impact on agronomic productivity and environment quality. Critical Reviews in Plant Sciences, 17(4): 319-464. doi: 10.1016/S0735-2689(98)00363-3

Leps J, Smilauer P, 2003. Multivariate Analysis of Ecological Data Using CANOCO. Bulletin of the Ecological Society of America, 22: 193. doi: 10.1017/CBO9781139627061

Li Bo, 1997. The rangeland degradation in North China and its preventive strategy. Scientia Agricultura Sinica, 30(6): 1-9. (in Chinese)

Li Jun, You Songcai, Huang Jingfeng, 2006. Spatial distribution of ground roughness length based on GIS in China. Journal of Shanghai Jiaotong University (Agricultural Science), 24(2): 185-189. (in Chinese)

Li Qingfeng, Li Fusheng, Siriguleng et al., 2001. A preliminary study of deerred grazing on grassland vegetation and animal production in a sandy grassland area. The China Grassland, 23(5): 41-45. (in Chinese)

Li Xiaobing, 2011. Impacts and Responses of Climatic Change on Temperate Grassland in Inner Mongolia. Beijing: Science Press, 10-25. (in Chinese)

Li Yubao, 2000. Soil erosion assessment for arid and semiarid areas. Journal of Arid Land Resources and Environment, 14(2): 48-52. (in Chinese)

Liu Aimin, Ci Longjun, 1997. A systematic analysis of the man-made influence in modern desertification process. Journal of Natural Resources, 12(3): 211-218. (in Chinese)

Liu Hantao, Ma Shuoshi, Dou Weiguo et al., 2006. The study on changing laws of wind-blown mass affected by stubble height. Journal of Arid Land Resources and Environment, 20(4): 182-185. (in Chinese)

Liu Jiyuan, Qi Yongqing, Shi Huading et al., 2007. Cs ${ }^{137}$ tracer analysis the soil wind erosion rate in Talia-Xilingol transect of Mongolia Plateau. China Academic Journal, 52(23): 27852791. (in Chinese)
Miao Zhong, 1996. Discussion about the crisis and protection of the grassland in Inner Mongolia. Inner Mongolia Prata Culture, 3(4): 1-3. (in Chinese)

Mu Shaojie, Li Jianlong, Chen Yizhao et al., 2012. Spatial differences of variations of vegetation coverage in Inner Mongolia during 2001-2010. Acta Geographica Sinica, 67(9): 1255-1268. (in Chinese)

MWRPRC (Ministry of Water Resources of the People's Republic of China), 2008. Standards for Classification and Gradation of Soil Erosion (SL190-2007). Beijing: Ministry of Water Resources of the People's Republic of China Press.

Nelson R G, Wagner L E, Stueve K, 1993. Mass reduction of standing and flat crop residues by selected tillage implements. In: Proceedings ASAE Winter Meeting, Chicago, IL Dec. 1417. Paper No. 932539. doi: 10.13031/2013.27848

Pimentel D, Kounang N, 1998. Ecology of soil erosion in ecosystems. Ecosystems, 1(5): 416-426. doi: 10.1007/s100219900035

Shao Yaping, 2008. Physics and Modelling of Wind Erosion (2th edition). Germany: Springer Netherlands Press, 3-5.

Shi Huading, Gao Qingxian, Qi Yongqing et al., 2009. Wind erosion hazard assessment of Mongolian Plateau by using FMCfuzzy cluster method. Journal of Natural Resources, 24(5): 881-889. (in Chinese)

Su Zhizhu, Lu Qi, Wu Bo et al., 2006. Potential impact of climatic change and human activities on desertification in China. Journal of Desert Research. 26(3): 329-335. (in Chinese)

Van Pelt R S, Zobeck T M, Potter K N et al., 2004. Validation of the wind erosion stochastic simulator (WESS) and the revised wind erosion equation (RWEQ) for single events. Environmental Modelling \& Software, 19: 191-198. doi: 10.1016/ S1364-8152(03)00122-1

Wang Juan, Li Baolin, Yu Wanli, 2012. Analysis of vegetation trend and their causes during recent 30 years in Inner Mongolia Autonomous Region. Journal of Arid Land Resources and Environment, 26(2): 132-138. (in Chinese)

Woodruff N P, Siddoway F H, 1965. A wind erosion equation. Soil Science Society of America Journal, 29(5): 602-608. doi: 10.2136/sssaj1965.03615995002900050035x

Xu Zhixin, Bai Yongfei, 1997. Grassland degradation and climate change. Foreign Zoo Technics: Grassland and Pasture, 78(3): 16-20. (in Chinese)

Yan Ping, Dong Guangrong, 2003. Application of the Caesium-137 technique on wind erosion in the GONGHE basin, Qinghai Province. Acta Pedologica Sinica, 40(4): 497-503. (in Chinese)

Yang Guanghua, Bao Anming, Chen Xi et al., 2010. Wind erosion hazard assessment in Xin Jiang based on RBFN model. Journal of Desert Research, 30(5): 1137-1145. (in Chinese)

Zhang Guoping, Zhang Zengxiang, Liu Jiyuan, 2001. Spatial distribution of aeolian erosion of soil and its driving factors in China. Acta Geographic Asinica, 56(2): 146-158. (in Chinese)

Zobeck T M, 1991. Abrasion of crusted soils: influence of abrader flux and soil properties. Soil Science Society of America Journal, 55(4): 1091-1097. doi: 10.2136/sssaj1991.036159950055 $00040033 x$ 